\title{
PROJETO INTEGRADOR ESTUDO E DIAGNÓSTICO DA BACIA HIDRO- GRÁFICA DE UM AFLUENTE DO CÓRREGO DO RIO SANTO ANASTÁCIO.
}

\section{STUDY INTEGRATOR STUDY AND DIAGNOSIS OF THE HYDROGRAPHIC BASIN OF A STREAM INFLUENT OF THE SANTO ANASTÁCIO RIVER.}

\author{
Bruno Minini Lage Fernandes ${ }^{1}$; Josi Carla Fernandes²; Victor Hugo Prates ${ }^{3}$; \\ João Gumercindo Junior ${ }^{4}$. \\ ${ }^{1}$ Universidade do Oeste Paulista - UNOESTE, Faculdade de Engenharia, Presidente \\ Prudente- Brasil \\ E-mail: brunomlfernandesbio@gmail.com
}

RESUMO - A humanidade encontra-se em um período de grandes desafios. $O$ momento exige imediata atenção, pois são constantes as transformações a enfrentarem-se neste século. As catástrofes humanas que vivemos anualmente no Brasil não são acontecimentos naturais, e sim um fenômeno urbano, de ganância imobiliária e desrespeito público que permite a ocupação de áreas ambientalmente vulneráveis. $O$ objetivo do projeto integrador é o estudo da micro bacia hidrográfica que tem como corpo hídrico o afluente do córrego Rio Santo Anastácio localizado em Presidente Prudente - SP. A metodologia utilizada tratou-se da escolha da área com no mínimo $1 \mathrm{~km}^{2}$ de área e ser uma micro bacia, a qual foi demarcada através do uso do software Google Earth Pro, onde foram analisados os aspectos hidrológicos, impactos ambientais, e saneamento básico. Os resultados obtidos mostraram que a bacia do córrego estudado possui grandes níveis de degradação devido ao assoreamento e mau uso do solo das propriedades do seu entorno, havendo poucas áreas de preservação permanente preservadas, além de descarte irregular de resíduos sólidos. Dessa forma conclui-se que são necessários mais estudos da bacia em questão, e os mesmos corroboram os resultados obtidos em estudos realizados nos córregos do Cedro e Cedrinho.

Palavras-chave: corpo hídrico; micro bacia; erosão; resíduos.

ABSTRACT - Humanity finds itself in a period of great challenges. The memories need to be answered, because they are constant as transformations to face the century. The human catastrophes that live annually are not of a variable nature, but an urban phenomenon, with capacity to project and disrespect that allows the accomplishment of an environmentally integrated water project, the tributary of the Rio Santo Anastácio stream located in Presidente Prudente - SP. The methodology used is the choice of the area with a minimum of $1 \mathrm{~km}^{2}$ of area and is a micro basin, an area demarcated through the use of Google Earth Pro software, where the hydrological aspects, the environmental impact and the basic sanitation were submitted. The results were similar to a basin of studied streams with high levels of degradation due to the silting and poor use of the soil of the surrounding properties, with few permanent preservation areas preserved, besides the irregular waste disposal. In this way, the results can be more favorable in relation to the question, and the same results corroborate the studies carried out in the streams of Cedro and Cedrinho Keywords: water body; micro basin; erosion; waste. 


\section{INTRODUÇÃO}

O presente projeto foi desenvolvido com o intuito de ampliar as competências adquiridas ao longo do curso e a integração delas, o estudo da micro bacia hidrográfica teve como escolha por ser uma unidade de gestão de elementos naturais e sociais onde é possível acompanhar as mudanças geradas pelo homem e a resposta da natureza.

Tendo em vista estes aspectos, pretende-se ser feito neste trabalho o estudo da área escolhida, realizando levantamento de dados em relação a geologia, pedologia, hidrologia, economia e social da área. Dessa maneira, poderá ser entendido como a micro bacia hidrológica reagiu a intervenção do homem.

Para tanto, foi realizado visitas in loco, para observar fauna e flora, como também entrevistas como os moradores da região. Uma vez que foi realizado visita foi levantado alguns problemas na bacia recorrente a intervenção do homem, como por exemplo invasão de APP (Área de Preservação Permanente), soterramento da nascente, descarte irregular de resíduos e assoreamento do córrego.

Nesse sentido o presente trabalho teve como objetivo levantar os aspectos e impactos ambientais gerados, dados sobre a hidrologia e problemas geotécnicos assim como problemas relacionados ao saneamento e saúde ambiental e dessa forma propor medidas mitigatórias.

\section{IDENTIFICAÇÃO E CARACTERIZAÇÃO DA ÁREA}

\subsection{Localização da área de estudo}

A área de estudo compreende a um afluente do Rio Santo Anastácio, o qual segundo as pessoas residentes no local não possui nome, onde as nascentes localizam-se próximos ao Rancho Quarto de Milha, Rodovia Assis chateaubriand SP-425 (SPM-425-E).

Figura 1. Bacia hidrográfica de estudo do Projeto Integrador. Fonte: Autores (2018)

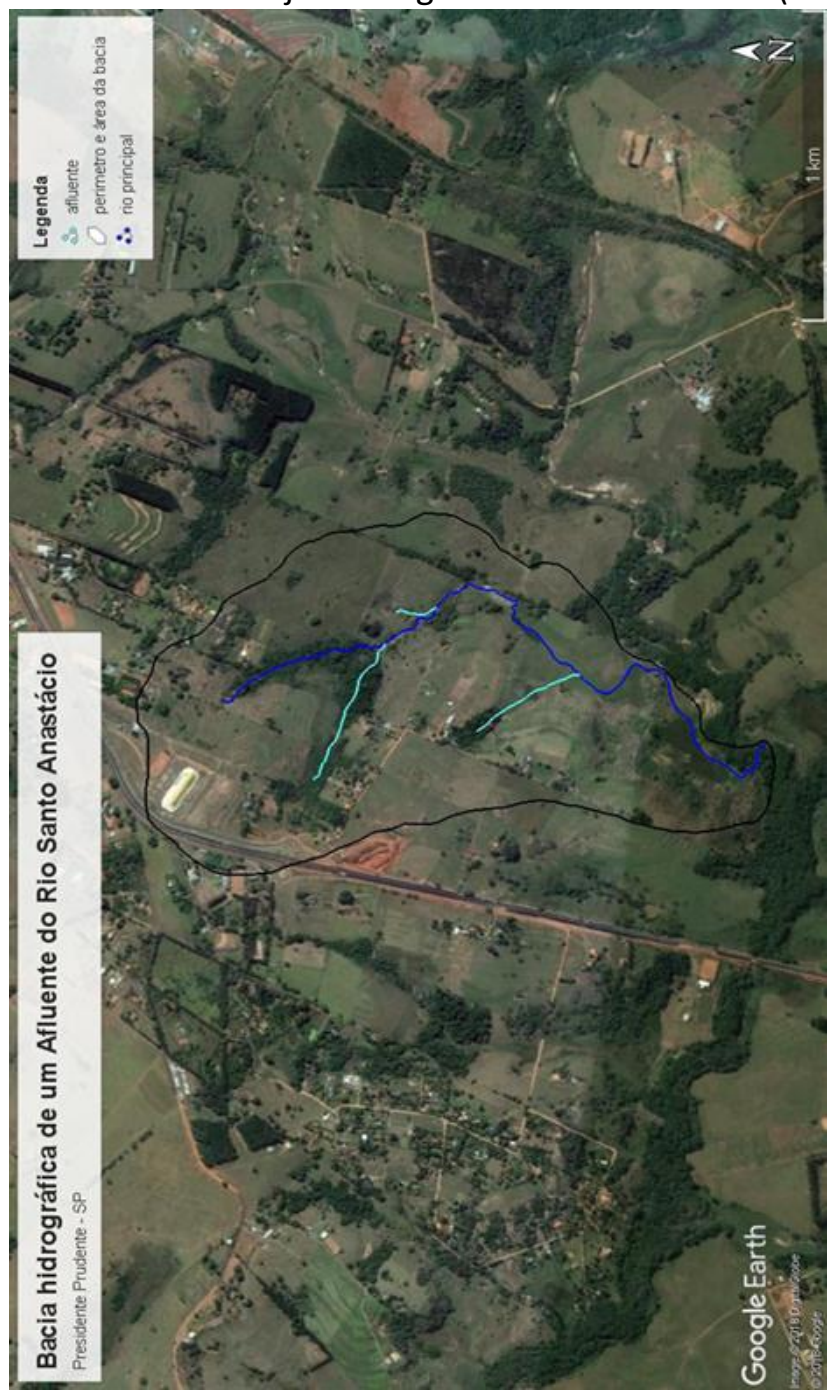




\section{DIAGNÓSTICO DA BACIA HIDROGRÁFICA}

Para que pudéssemos efetuar os estudos, foi necessário pedir autorização para um dos moradores da área, o qual nos levou até um trecho mais plano do afluente. Durante a entrevista ao mesmo sobre as condições de sua propriedade e do regime de cheias do curso d'água, nos foi esclarecido que em tempos de seca o córrego praticamente seca, ficando somente uma pequena lamina d'água, quando em períodos de seca severa o mesmo fica somente com o leito de terra exposto, sem água.

Durante a caminhada foi possível perceber que se trata de um terreno de inclinação acentuada, de composição de solo fraca de textura arenosa e bem susceptível a lixiviação, com poucas áreas de proteção permanente, e quando existem não respeitam os 15 metros mínimos exigidos para a classificação deste tipo de córrego. Foi observado que nas propriedades ao redor todas possuem curvas de nível, e não foi possível observar grandes erosões no local, somente pequenas ravinas feitas pelos bois (caminho de boi).

Um dos fatores que até o momento mais chamaram a atenção é o fato de que a nascente de um dos braços do afluente foi, segundo os moradores locais, aterrada após a construção de uma ponte para um trevo de veículos na Rodovia Assis chateaubriand, e a princípio foi feito um barramento para a água da mesma, porem com a quantidade de terra extraída do local e depositada próxima, esta foi aterrada, sobrando somente um pequeno olho d'água, o qual não conseguimos acessar, pois trata-se de uma área de mata bem fechada e dentro de outra propriedade particular.

Segundo o dono da propriedade, encontrar o local exato da foz deste afluente será algo muito difícil, pois quando chove, desce um grande volume de água que toma grande parte das margens, e se espalha pelo pasto, e da mesma forma ocorre com o Rio Santo Anastácio, que transborda e atinge áreas de vale, que ficam por muito tempo alagadas, criando áreas de várzea praticamente permanentes, e que segundo o proprietário, nem os animais seguem por estes caminhos, tornando talvez a nossa chegada até a foz do afluente mais difícil do que imaginávamos.
Figura 2. Curso natural do afluente, sem área de preservação permanente, com evidentes processos de erosão laminar. Fonte: Acervo dos autores, 2018.

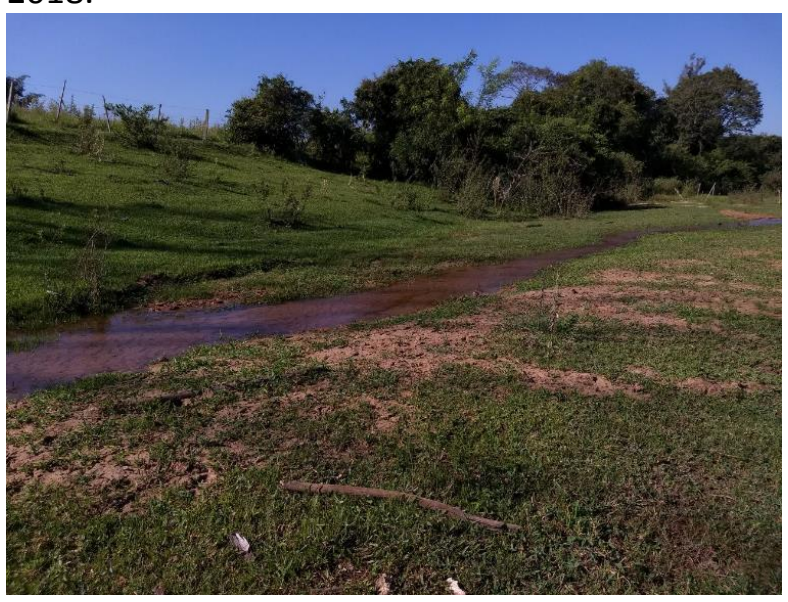

\section{USO E OCUPAÇÃO DO SOLO}

A identificação do uso e da ocupação auxilia no controle da densidade populacional e na ocupação pelas construções, podendo aperfeiçoar os deslocamentos e melhorar a mobilidade; evitar as incompatibilidades e as possibilidades de desastres ambientais além de, preservar o meio ambiente e a qualidade de vida.

Estudos que possam identificar o uso e a ocupação do solo são essenciais, pois as formas de utilização têm provocado sucessivos e inúmeros problemas ambientais, que promovem intensa degradação ao meio ambiente, tais como: contaminação do solo e água, poluição do ar, perda da capacidade de produtividade dos solos, erosão, entre tantos outros (SANTOS \& BECKER, 2006).

O uso e ocupação do solo na região de estudo segue o mapeamento realizado no Plano Diretor de Controle de Erosão Rural, e as visitas técnicas ao local também confirmaram o mapeamento realizado. Dessa forma o solo da região de estudo consiste quase em sua totalidade de uso destinada para a agropecuária, com mais uso somente na pecuária, provavelmente devido a alta declividade do terreno, impossibilitando o cultivo de determinadas culturas agrícolas.

\section{METODOLOGIA}

\subsection{Demarcação da área de estudo}

A área de estudo escolhida em primeira mão tratava-se de um afluente do córrego do Cedro, no entanto, a micro bacia formada seria de grande extensão, sendo inviável para o atual 
estudo. Dessa forma foi escolhida uma nova área, sendo esta um conjunto de afluentes do Ribeirão do Rio Santo Anastácio, que respeitaram os dois critérios exigidos para o projeto que são:

- Ser uma micro bacia;

- Ter ao menos $1 \mathrm{~km}^{2}$ de área;

\subsection{Análise dos impactos ambientais}

A avaliação dos impactos ambientais na área de estudo foi realizada através de visitas técnicas, onde foram identificados diversos problemas devido a forma de ocupação da área, tipos de cultivos existentes e tipo de pecuária feita na área, assim como também foram verificados o cumprimento da lei em relação ao respeito as áreas de proteção ambiental (APP), processos erosivos, vazão do córrego (visual e entrevista com moradores locais) e outros aspectos que compõem o quadro de impactos ambientais.

\subsection{Hidrologia}

Os cálculos hidrológicos utilizados são uma serie de fórmulas matemáticas próprias para determinas as características da bacia hidrográfica, usando os dados sobre a área $(A)$, perímetro (P) e o corpo hídrico (L e Lt) conseguidos por meio de ferramentas do Google Earth Pro. Foram calculados as variáveis: Coeficiente de Compacidade (kc), Fator Forma (kf), Densidade de Drenagem (Dd) e Extensão média de escoamento superficial (I) por meio desses cálculos.

\subsection{Determinação da forma da bacia}

A forma de uma bacia influencia no tempo de concentração, que é o tempo gasto pela água que caiu nos limites mais distantes do ponto de saída para atingir a saída da bacia hidrográfica (ponto crítico).

\subsection{Coeficiente de compacidade ( $\mathrm{Kc}$ )}

Este parâmetro, compara a forma da bacia em questão, com um círculo de igual área.

Então:

$\mathrm{Kc}=0,28 \frac{5,31}{\sqrt{1,5}}=1,21$

Portanto, a Bacia hidrográfica, apresenta uma menor tendência de enchentes, pois está não é parecida com um círculo, sendo assim mais irregular e o seu tempo de concentração é maior.

\subsection{Fator forma (kf)}

Este parâmetro compara a bacia hidrográfica em questão com um quadrado de igual área.

$$
\begin{aligned}
& \text { Então: } \\
& \mathrm{Kf}=\frac{1,5}{2,41^{2}}=0,2582
\end{aligned}
$$

Sendo assim, a Bacia hidrográfica, é menos semelhante com um quadrado, sendo está mais irregular e apresentando uma menor tendência de enchentes e um maior tempo de concentração.

\subsection{Densidade de drenagem (dd)}

É a relação entre o comprimento total dos cursos d'água existentes na bacia hidrográfica e a área da bacia. Fornece uma indicação da eficiência de drenagem da bacia.

$$
\begin{aligned}
& \text { Então: } \\
& \mathrm{Dd}=\frac{3,41}{1,5}=2,2733 \mathrm{~km} / \mathrm{km}^{2}
\end{aligned}
$$

A Bacia hidrográfica, possui uma densidade de drenagem moderada de acordo com os métodos para análise, e um moderado tempo de concentração.

\subsection{Extensão média de escoamento superficial (I)}

É a distância média que seria percorrida pela gota d'água de chuva, em linha reta, para atingir o ponto mais próximo de um curso de água qualquer.

$$
\begin{aligned}
& \text { Então: } \\
& \mathrm{I}=\frac{1,5}{4 \times 3,41}=0,1099 \mathrm{Km}=109,9 \mathrm{~m}
\end{aligned}
$$

$\mathrm{Na}$ Bacia, o valor da extensão média de escoamento superficial foi maior que $100,00 \mathrm{~m}$, possuindo então extensão elevada, com menor tendência de enchentes, e um maior tempo de concentração.

\subsection{Declividade do talvegue (st)}

Influi diretamente na velocidade da água que atinge os cursos d'água da bacia. Quanto maior a declividade do talvegue, maior será a velocidade de escoamento da água, logo as enchentes serão mais pronunciadas (maior vazão máxima), porém de menor duração (enchentes rápidas e mais catastróficas).

\section{Declive simples do talvegue (St-1)}

St-1: Determinar a declividade simples St_1 $=\frac{\operatorname{cota} \mathrm{N}-\operatorname{cota} \mathrm{F}}{L}=\frac{420-371}{2410}==$ $0,02033 \mathrm{~m} / \mathrm{m}$ ou $2,033 \%$ ou $20,33 \mathrm{~m} / \mathrm{km}$ 
5.10 Tempo de concentração (tc)

É importante ressaltar que o Tc calculado pela fórmula a seguir é satisfatório quando a área da bacia em questão é menor que $4 \mathrm{~km}^{2}$, logo quanto maior a área maior será a imprecisão.

Equação de California Highway and Public Works

Então:

$$
T c=57 x\left(\frac{2,41^{3}}{420-371}\right)^{0,385}=35,18 \mathrm{~min}
$$

\section{RESULTADOS E DISCUSSÕES}

\subsection{Hidrologia}

Os estudos hidrológicos têm como principal objetivo caracterizar, quantificar e qualificar os corpos hídricos presentes na área de estudo podendo assim determinar as melhores formas e condições de uso ou não do seu potencial hídrico, assim como determinar os usos do seu entorno e medidas mitigatórias para a conservação e preservação dos corpos hídricos.

\subsection{Análise de impacto ambiental}

Aspecto Ambiental é toda ação que gera um impacto sendo ele positiva ou negativo, diferenciando-se assim de Impacto Ambiental a ser definido por qualquer alteração física, química ou biológica no meio ambiente resultante de atividades antrópicas.

A análise dos impactos ambientais é um tema que que dever ser abordado de forma abrangente, dentro desse tema existem várias vertentes que são sempre muito utilizadas. O cumprimento das leis seria uma maneira de diminuir os impactos gerados pela população que está no empreendimento em questão, uma fiscalização maior resolveria cerca $70 \%$ a $80 \%$ dos problemas gerados diariamente pela falta de informação e pela geração de resíduos.

\section{PROPOSTAS DE INTERVENÇÃO}

\subsection{Descarte de resíduos}

Deve-se fazer a aplicação da coleta seletiva e destinação correta dos resíduos. Seguindo a Lei Municipal $N^{\circ} 5660 / 01$ na qual no artigo $8^{\circ}$ cita "O Executivo Municipal, através da Companhia Prudentina de Desenvolvimento (PRUDEN$\mathrm{CO})$, promoverá a coleta, classificação e venda dos materiais selecionados em todo território do Município, conforme a Lei."

O local de estudo não está incluído dentro do perímetro urbano, sendo necessário rever a delimitação urbana do município, uma vez que o mesmo encontra-se em estagio de expansão, ou como alternativa, estudar a coleta de resíduos nas propriedades rurais próximas ao perímetro urbano.

\subsection{Contaminação do solo e corpo hídrico}

Para a contaminação do solo e corpo hídrico deve-se aplicar medidas com o fim de reduzir o impacto que já foi instalado nesses meios físicos, medidas tais como a conscientização dos moradores dos entornos a substituir as fossas negras das residências por conjuntos fossa/filtro ou biodigestores, ambos certificados pela ABNT/NBR para que possam ser descartados no solo através de sumidouros com carga de DBO aceitável para que não contaminem os lençóis freáticos existentes na bacia hidrográfica, consequentemente conservando os córregos em estudo.

\subsection{Invasão das Áreas de Proteção Permanente (APP)}

Como foram constatadas na área de estudos, grandes áreas ao longo do curso do córrego foram identificadas sem vegetação, assim como também mostram as imagens de satélite, na sua maioria devido ao uso incorreto e desordenado do solo para agricultura e pecuária, na intenção de ampliar as produções e aumentar o alimento disponível para o gado pastorear. Recomenda-se que sejam cercadas e protegidas, seguindo as diretrizes impostas pelo Código Florestal Lei no 12651/2012, na seção I Da Delimitação das Áreas de Preservação Permanente no Artigo $4^{\circ}$ inciso "I. a) 30 (trinta) metros, para os cursos d'água de menos de 10 (dez) metros de largura".

\subsection{Compactação do solo}

O solo como foi diagnosticado contém diversos pontos de interferência antrópica, no caso da área de estudo, essa compactação foi formada pela atividade pecuária existente em praticamente todas as áreas as margens do córrego, inclusive nas áreas de APP que deveria estar protegidas.

Para a redução desse impacto deve-se fazer o isolamento das áreas de APP seguido de revolvimento do solo e posterior plantio. Nas áreas fora de áreas de proteção, pode-se efetuar também o revolvimento do solo, com posterior plantio e correção das curvas de nível para evitar lixiviação de material particulado pelas aguas 
pluviais para o córrego.

\subsection{Erosão e assoreamento}

Para a erosão 01 que se encontra em estágio de voçoroca, pode ser feito remediação através do ajuste do talude, e plantio de gramíneas em grades de bambu para a fixação das mesmas, assim como revisão da efetividade das curvas de nível e se for o caso, refazer as mesmas.

Na erosão 02 e 03 ambas são erosões laminares, decorrentes do fluxo de aguas pluviais em velocidade e em terreno descoberto, e que coincidentemente estão dentro de áreas de APP. A solução deste problema também se dá com a correção das curvas de nível e proteção das áreas de APP, com o reflorestamento das mesmas.

\section{CONCLUSÃO}

Dessa forma conclui-se que os resultados obtidos corroboram outros estudos realizados nas bacias hidrográficas dos córregos do Cedro e Cedrinho e bacia hidrográfica do córrego do Embirí em que ambas desaguam no Rio Santo Anastácio e compartilham dos mesmos resultados obtidos como uso irregular de solos, invasão de APPs e descarte irregular de resíduos, contribuindo para a atual situação em que se encontra o Rio Santo Anastácio, com boa parte de seu curso d'água assoreado, com pontos de descarte clandestino de efluentes, e praticamente ausência de fauna em seu corpo hídrico.

\section{REFERÊNCIAS}

ARAÚJO, R.R., DIAS, L.S., BENINI, S.M. Água: Tratamento, Efluentes e Lodos. - Tupã: ANAP, 2015, p.129.

BRASIL, Ministério do Meio Ambiente, Conselho Nacional do Meio Ambiente - RESOLUÇÃO CONAMA LEI FEDERAL DE № 430/11 - Disponível em:<http://www.mma.gov.br/port/conama/legi abre.cfm?codlegi=646>. Acesso em: 12 Nov. 2017.

BRASIL, Sistema Nacional de Gerenciamento de Recursos Hídricos - POLÍTICA NACIONAL DE RECURSOS HÍDRICOS. Disponível em:

<http://www.planalto.gov.br/ccivil_03/leis/L943

3.htm>. Acesso em: 31 Out. 2017.
BRASIL, Subchefia para Assuntos Jurídicos - POLÍTICA NACIONAL DE RESÍDUOS SÓLIDOS LEI DE № 12305/2010 - Disponível em:

<http://www.planalto.gov.br/ccivil_03/_ato2007 -2010/2010/lei/l12305.htm>. Acesso em: 12 Nov. 2017.

\section{COMITÊ DA BACIA HIDROGRÁFICA DO PONTAL DO PARANAPANEMA - Plano de}

Bacia Hidrográfica do Pontal do Paranapanema (urghi-22), Relatório I, Volume I- 2015.

MINISTÉRIO DO MEIO AMBIENTE, CONSELHO NACIONAL DO MEIO AMBIENTE - RESOLUÇÃO CONAMA LEI FEDERAL DE № 430/11 disponível em <http://www.mma.gov.br/port/conama/legiabre .cfm?codlegi $=646>$ acesso em 12 de novembro de 2017.Traduzido por NETO, H.B. - Projeto Solo na Escola - UFPR, Disponível em < http://www.escola.agrarias.ufpr.br/arquivospdf/ pai_pedologia.pdf> Acesso em 09 de Novembro de 2017.

SANTOS, M.; BECKER, B. K. (Org.) Territórios, territórios. Rio de Janeiro: DP\&A, 2006. p.12545. 